\title{
Effects of Surface Finish, Heat Treatment and Cold Working on the Wettability of Solid Copper by Liquid Tin
}

\author{
By Amal. T. Hasouna*, K. Nogi** and K. Ogino**
}

\begin{abstract}
The sessile drop method was used to study the effects of surface finish, heat treatment and cold working on the wettability of solid $\mathrm{Cu}$ by liquid $\mathrm{Sn}$. Wettability was evaluated by measuring the angle of contact between the solid and the liquid phases. It was found that electrolytic polishing is better for obtaining good wetting than mechanical polishing. It was also indicated that annealing of solid $\mathrm{Cu}$ substracts could promote the wettability depending on the annealing period. Cold working was also found to have an influential effect on the wettability depending on the process and the degree of cold working. (Rolling promotes the wetting by decreasing the value of the contact angle of both mechanically and electrolytically polished $\mathrm{Cu}$ substrates, while pressing does not cause a significant effect on the contact angle of the mechanically polished samples but has an influential effect on the contact angle of the electrolytically polished samples). These results were discussed in relation to the crystal orientation and surface energy of the solid $\mathrm{Cu}$ substrates.
\end{abstract}

(Received May 26, 1988)

Keywords: wettability, wetting, spreading, contact angle, surface finish, surface energy, heat treatment, cold working

\section{Introduction}

The phenomena of wetting and spreading are of prime importance in many engineering fields. In metallurgy, these phenomena are of particular interest because of problems arising in brazing and coating.

Sessile drop experiments have been widely used to study solid-liquid interfaces. In a sessile drop experiment wetting corresponds to the reduction of the surface energy of the solid by the liquid $\left(\gamma_{1 s}<\gamma_{s}\right)$ with the formation of a steady acute contact angle.

The wettability of a solid surface by a liquid depends upon the relative magnitudes of the surface energies of the solid surface $\gamma_{\mathrm{s}}$, liquid surface $\gamma_{1}$, and solid-liquid interface $\gamma_{1 s}$.

At the line of contact of the liquid with the solid the relationship (1), which was first introduced by Young ${ }^{(1)}$ in 1805 , and was later demonstrated on thermodynamic grounds by

* Graduate Student, Osaka University.

** Department of Materials Science and Processing, Faculty of Engineering, Osaka University, 2-1 Yamadaoka, Suita, Osaka 565, Japan.

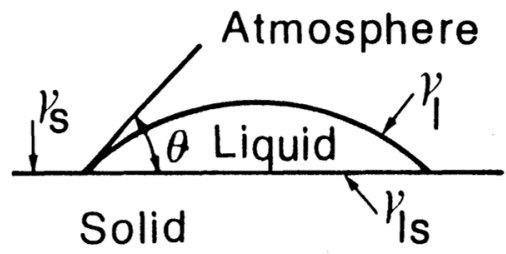

$$
v_{\mathrm{s}}=\gamma_{1} \cos \theta+v_{1 \mathrm{~s}}
$$

Fig. 1 Surface free energies in a system consisting of a liquid drop on a solid surface at equilibrium state.

$\mathrm{Gibbs}^{(2)}$ and more recently by Johnson ${ }^{(3)}$, must be applicable where $\gamma$ is the surface free energy and $\theta$ the contact angle at which the liquid meets the solid as defined in Fig. 1.

$$
\gamma_{\mathrm{s}}=\gamma_{1} \cos \theta+\gamma_{\mathrm{ls}}
$$

Many investigators ${ }^{(4)-(11)}$ have studied the principles which govern wetting and spreading in metal-metal systems at temperatures at which one is a liquid. Most of them attributed good wetting to the solubility, surface roughness or the interfacial energy. No attempt has been made to go into the details of the crystal orientation of the base metal and its 
effect on the wettability.

In the present work, the effects of surface finish, heat treatment and cold working of solid $\mathrm{Cu}$ substrates were investigated and the results were discussed in relation to the crystal orientation and the surface energy of the solid $\mathrm{Cu}$ substrates. These results were discussed taking into account the effect of crystal orientation.

\section{Experimental}

\section{Materials}

Pure tin shot and copper substrates were obtained and prepared as explained in detail in a previous paper ${ }^{(12)}$. Only a brief description of preparation will be given here. $\mathrm{Cu}$ of $99.99 \%$ purity was received in a form of sheet, (as rolled and without annealing), of $3 \mathrm{~mm}$ thickness and cut into small substrates of $30 \mathrm{~mm} \times 25$ $\mathrm{mm}$. After carrying out the mechanical polishing of the $\mathrm{Cu}$ substrates on emery papers as explained in Ref. (12), they were electrolytically polished. The solution, current and
Table 1 The solution, cathode, voltage, current, temperature and time used for electrolytic polishing of $\mathrm{Cu}$ substrates.

\begin{tabular}{|c|c|c|c|c|c|c|}
\hline Metal & Solution & Cathode & $\begin{array}{c}\text { Voltage } \\
\text { across } \\
\text { cell }\end{array}$ & $\begin{array}{l}\text { Current } \\
\text { (A) }\end{array}$ & $\begin{array}{c}\text { Temp. } \\
(\mathrm{K})\end{array}$ & $\begin{array}{c}\text { Time } \\
(\mathrm{ks})\end{array}$ \\
\hline $\mathrm{Cu}$ & $\begin{array}{l}\text { phosphoric } \\
\text { acid } 50 \% \\
\text { concentration }\end{array}$ & $\begin{array}{l}\mathrm{Cu} \\
\mathrm{n}\end{array}$ & 9 & $1.5-2$ & $\begin{array}{c}\text { below } \\
303\end{array}$ & $\int_{0.12}^{0.06}$ \\
\hline
\end{tabular}

temperature used for electrolytic polishing are shown in Table 1.

Annealing treatments were carried out with specimens for $0.06,1.8$ and $7.2 \mathrm{ks}$ in $\mathrm{H}_{2}$ atmosphere and at temperatures approximately $300 \mathrm{~K}$ above the testing temperatures.

Surface roughness was measured for both mechanically, electrolytically polished and annealed samples. No significant difference in surface roughness was detected.

\section{Apparatus and Method}

The sessile drop method was used to study the effects of surface finish, heat treatment and

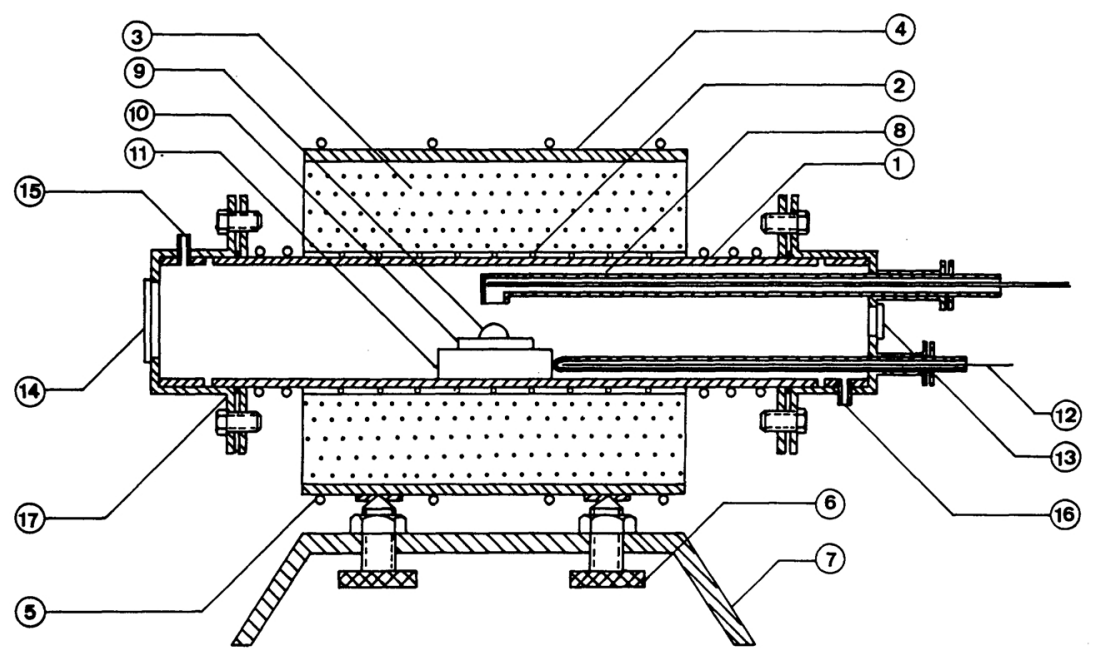

Fig. 2 Sectional diagram of furnace used for the wetting test.

1. Reaction tube

2. Nichrom wire heater

3. Asbestos

4. Iron cylinder

5. Cooling pipe

6. Leveling screw

7. Base

8. Metal dropping assembly
9. Metal drop

10. Solid substrate

11. Alumina plate

12. Thermocouple

13. Window for lighting

14. Observation window

15. Gas inlet

16. Gas outlet

17. O-Ring 
cold working on the wettability of solid $\mathrm{Cu}$ by liquid $\mathrm{Sn}$. The apparatus used is shown in Fig. 2. The wetting tests were carried out in $\mathrm{H}_{2}$ atmosphere. The methods used to carry out these tests are given in the previous paper ${ }^{(12)}$.

The degree to which the liquid wets the solid was evaluated by measuring the angle of contact between the liquid and the solid after reaching an equilibrium state after $3.6 \mathrm{ks}$ from the dropping moment. Two techniques of calculations were used depending on the resulted contact angle $\left(\theta<90^{\circ} \text { or } \theta \geqslant 90^{\circ}\right)^{(12)}$.

\section{Results and Discussion}

\section{Effect of surface finish}

The behaviour of a liquid on a solid metallic surface depends entirely upon the condition of the surface. In the present work, two kinds of surface finish were used; mechanical polishing and electrolytic polishing. Electrolytic polishing produces a smooth and brilliant surface by the selective removal of metal from the surface by anodic action.

It is well known that the metallurgical properties of the surface layer in a rubbed, rolled or slided surface are remarkably different from the bulk of the material. This layer is known as the Beilby layer ${ }^{(13)}$. A schematic representation of this layer is given in Fig. 3. It is considered as a very fine grained structure resulting from repeated deformation of the solid surface. Both the mechanically and electrolytically polished samples were examined by Electron
Probe Microscopic Analysis (EPMA). The results given in Fig. 4 indicate the existence of a fine grained layer in the vicinity of the surface of the mechanically polished samples. However this layer was not observed in the electrolytically polished or annealed samples as shown in Figs. 5 and 6, respectively. Table 2 indicates that in the case of no heat treatment the contact angle of the mechanically polished specimen is larger than that of the elec-

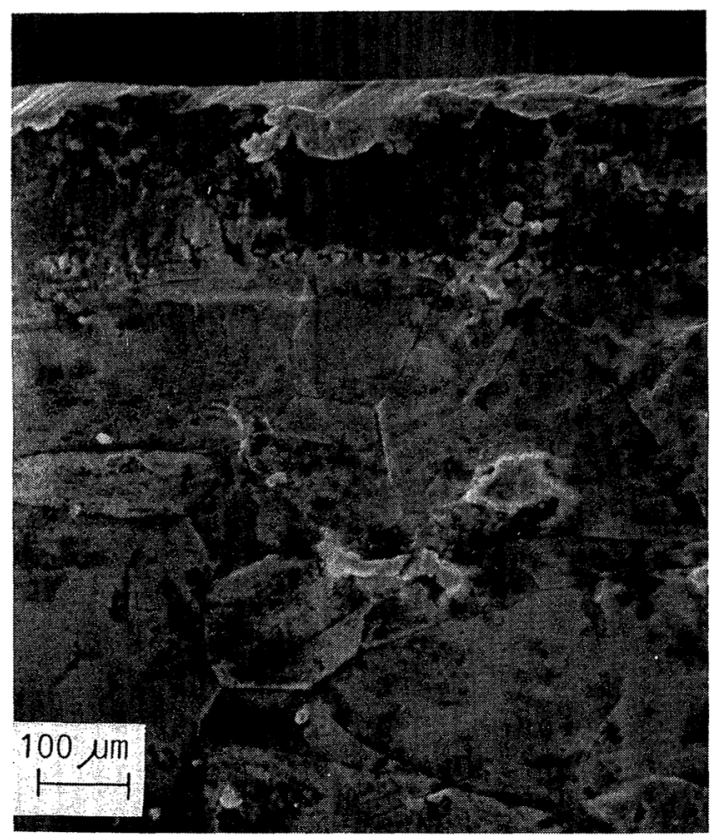

Fig. 4 SEM image of a mechanically polished $\mathrm{Cu}$ substrate indicating the grain size in the vicinity of the surface.

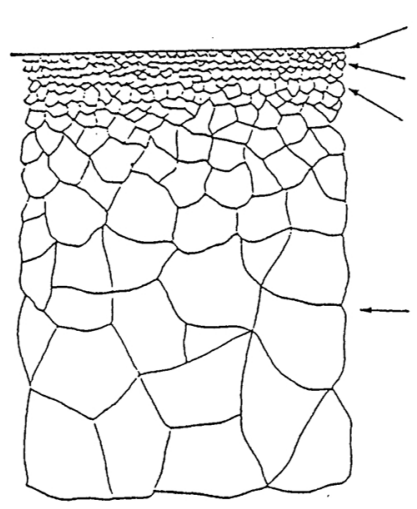

Gas adsorbed layer (c.a. 0.2-0.3nm)

Beilby layer (c.a. $10 \mathrm{~nm}$ )

Fine grain layer (c.a. $100 \mathrm{~nm}$ )

Plastic deformed layer

Fig. 3 Typical representation of surface and bulk layers of plastically deformed metal. 


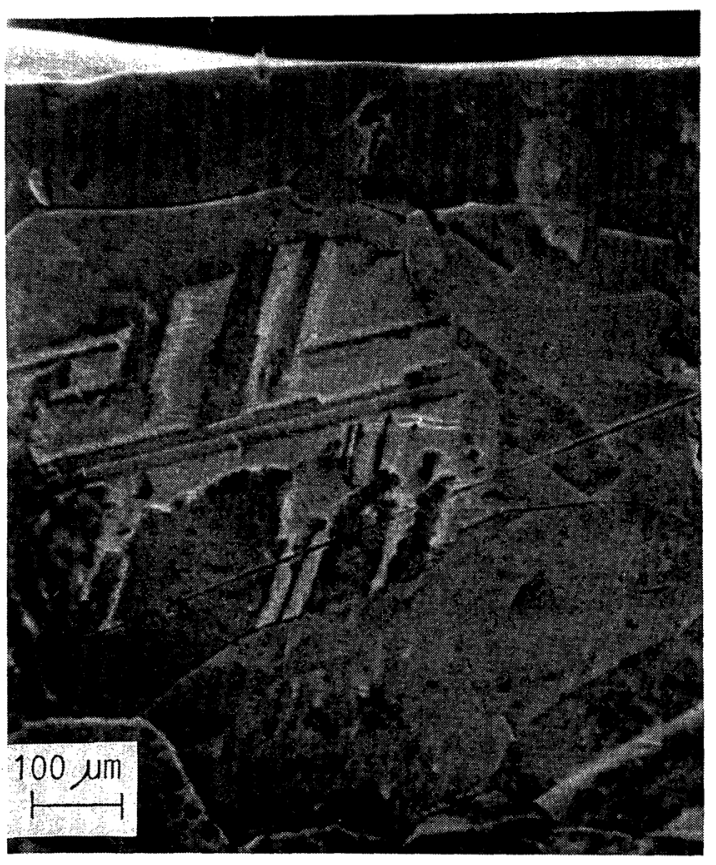

Fig. 5 SEM image of an electrolytically polished $\mathrm{Cu}$ substrate indicating the grain size in the vicinity of the surface.

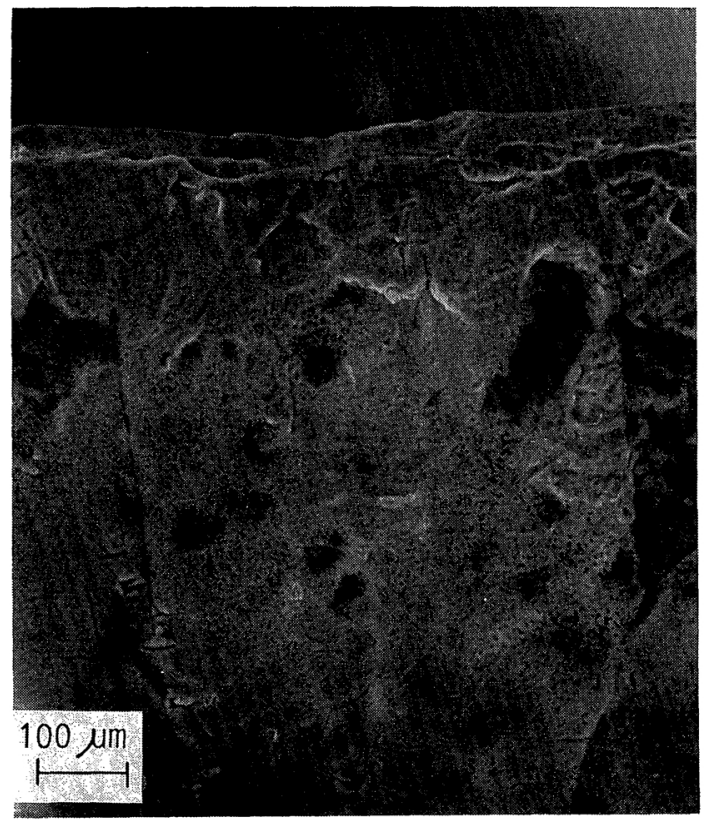

Fig. 6 SEM image of a $\mathrm{Cu}$ substrate annealed at $1073 \mathrm{~K}$ in $\mathrm{H}_{2}$ atmosphere indicating the grain size in the vicinity of the surface.
Table 2 Values of the angle of contact between liquid Sn drop and solid $\mathrm{Cu}$ substrate under various experimental conditions.

\begin{tabular}{|c|c|c|c|c|c|}
\hline \multirow{3}{*}{$\underset{(\mathrm{K})}{\text { Temp. }}$} & \multicolumn{4}{|c|}{ Contact angle } & \multirow{3}{*}{ Atmosphere } \\
\hline & \multicolumn{2}{|c|}{$\begin{array}{l}\text { Mechanical } \\
\text { polishing }\end{array}$} & \multicolumn{2}{|c|}{$\begin{array}{l}\text { Electrolytic } \\
\text { polishing }\end{array}$} & \\
\hline & $\begin{array}{c}\text { Without } \\
\text { H.T. }\end{array}$ & $\begin{array}{l}\text { With } \\
\text { H.T. }\end{array}$ & $\begin{array}{c}\text { Without } \\
\text { H.T. }\end{array}$ & $\begin{array}{l}\text { With } \\
\text { H.T.* }\end{array}$ & \\
\hline 573 & $58^{\circ}$ & $36^{\circ}$ & $47^{\circ}$ & $49^{\circ}$ & \multirow{4}{*}{$\mathrm{H}_{2}$} \\
\hline 673 & $42^{\circ}$ & $25^{\circ}$ & $20^{\circ}$ & $20^{\circ}$ & \\
\hline 793 & $23^{\circ}$ & $13^{\circ}$ & $9^{\circ}$ & $8^{\circ}$ & \\
\hline 923 & $0^{\circ}$ & $0^{\circ}$ & $0^{\circ}$ & $0^{\circ}$ & \\
\hline
\end{tabular}

*Heat treatment for $0.06 \mathrm{ks}$ in $\mathrm{H}_{2}$ atmosphere at temperatures approximately $300 \mathrm{~K}$ above the testing temperatures.

trolytically polished one at the same testing temperature. This may be attributed to the increase of the Beilby layer due to mechanical polishing meaning change of the orientation of the surface, and correspondingly change of the surface energy of the solid $\mathrm{Cu}$ as will be explained later. But from the same table in the case of annealing it can be noticed that there is no big difference between the contact angle of the mechanically and electrolytically polished samples, indicating that heat treatment which were carried out after mechanical polishing has approximately the same effect of the electrolytic polishing on the contact angle. Since both of them decrease the intensity of the (111) plane.

In the case of electrolytic polishing the contact angle was smaller than that of the case of mechanical polishing because the electrolytic polishing is accompanied with a dissolution of a surface layer which involves the Beilby layer affecting the wetting. The electrolytic Polishing has the same effect of recovery and/or recrystallization which may be caused by annealing. It is very difficult to determine the exact increase or decrease of the thickness for the Beilby layer because it is so thin. However, it is possible to obtain an approximate evaluation of the layer and to clarify the possibility of its removal by electrolytic polishing process. This was carried out in the present work by weighting the $\mathrm{Cu}$ substrate before and after the electrolytic polishing, then by measuring the 
volume of the substrate and with the known value of copper density it was found that the thickness of the layer which could be removed by electrolytic polishing process was about 30 $35 \mu \mathrm{m}$.

For more clarification of the effect of surface finish on the wettability, an interesting experiment in which half of the $\mathrm{Cu}$ substrate surface was polished by emery papers and the other half by electrolytic polishing, was carried out at $673 \mathrm{~K}$ in $\mathrm{H}_{2}$ atmosphere. Figure 7 shows the shape of the Sn drop after solidification. As can be noticed from the figure, there is a thin grey band around the half of the Sn drop

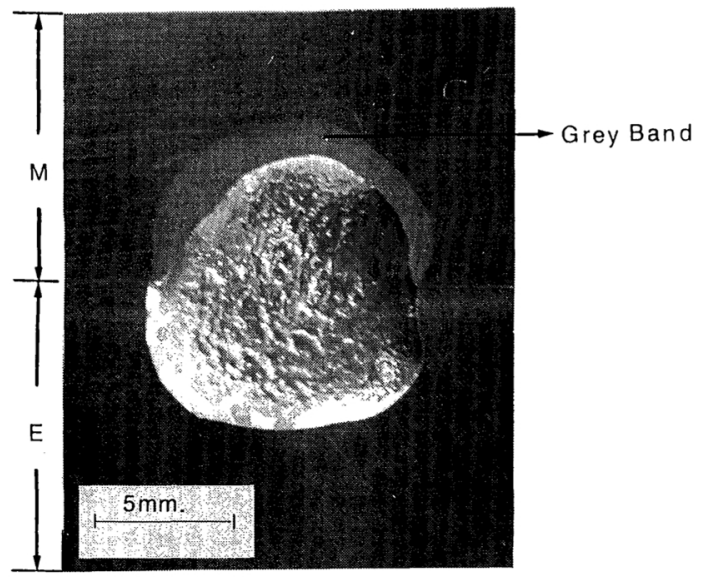

Fig. 7 Solidified shape of a liquid $\mathrm{Sn}$ drop on a solid $\mathrm{Cu}$ substrate, M: Mechanically polished side. E: electrolytically polished side.

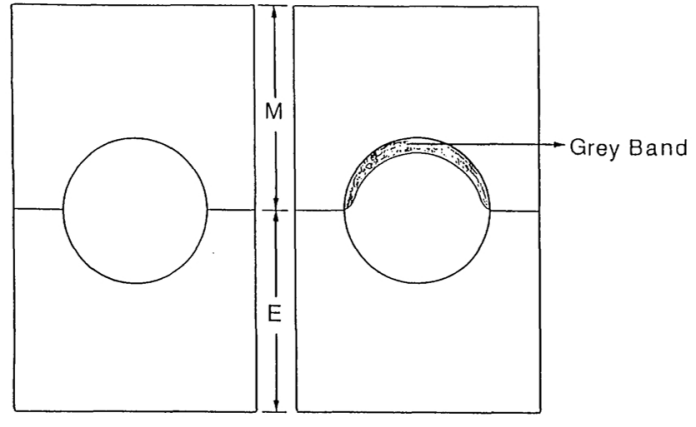

(a)

(b)

Fig. 8 Schematic representation of the wetting test carried out at $673 \mathrm{~K}$ in $\mathrm{H}_{2}$ atmosphere. (a) just after dropping. (b) after time progress. M: mechanically polished side. E: electrolytically polished side. which lies on the mechanically polished side. As shown in Fig. 8(a) initially, just after dropping, symmetrical shap of the two halves of the drop in both the mechanically and the electrolytically polished sides can be noticed. After the elapse of time the Sn drop, however, moved towards the electrolytically polished side leaving this grey band on the surround of the Sn drop which lies on the mechanically polished side as shown in Fig. 8(b). This may indicate that liquid Sn has a tendency to spread on the electrolytically polished $\mathrm{Cu}$ substrate more than the mechanically polished one. It may be attributed to the difference of the crystal orientation and thus of the surface energy between the mechanically and electrolytically polished $\mathrm{Cu}$ substrates as will be clarified later by X-ray examination.

\section{Effect of heat treatment}

Figure 9 shows the dependence of the contact angle on the annealing periods. From the figure it can be noticed that wetting is the best in the case of annealing for $0.06 \mathrm{ks}$. This result will be discussed in a later section by X-ray analysis method. Table 2 indicates that the contact angles of the mechanically polished $\mathrm{Cu}$ substrates which annealed for $0.06 \mathrm{ks}$ in $\mathrm{H}_{2}$ atmosphere are smaller than those which were not annealed. The same tendency was observed when the samples annealed for 1.8 and $7.2 \mathrm{ks}$ in-spite of the difference of the values of the contact angles according to the annealing period. However this effect was not observed in the case of electrolytically polished samples

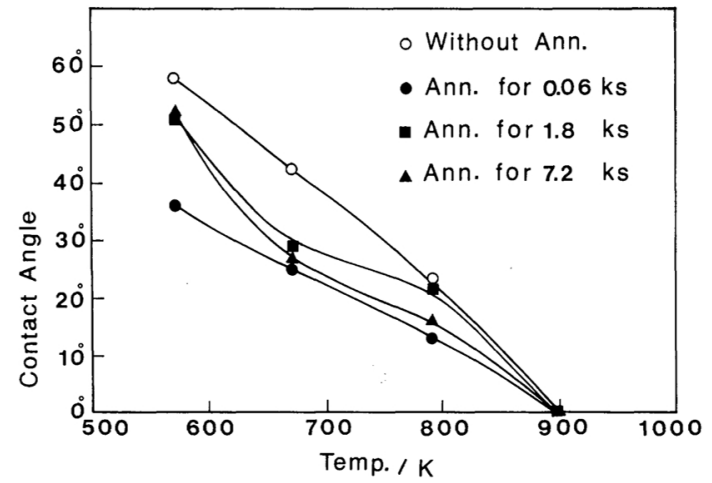

Fig. 9 Relationship between contact angle and annealing periods at different temperatures. 


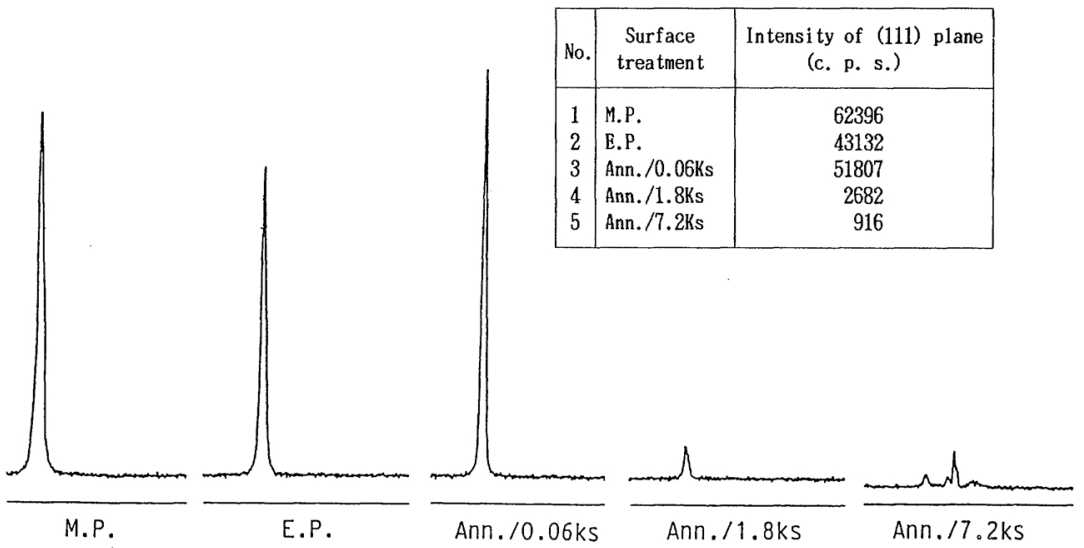

Fig. 10 Diffraction pattern indicating the intensity of (111) plane at angular position $2 \theta=43.2^{\circ}$ of mechanically polished $\mathrm{Cu}(1)$, electrolytically polished (2), annealed for $0.06 \mathrm{ks}$ at $1073 \mathrm{~K} \mathrm{(3)}$, annealed for $1.8 \mathrm{ks}$ at $1073 \mathrm{~K}(4)$, annealed for $7.2 \mathrm{ks}$ at $1073 \mathrm{~K} \mathrm{(5).} \mathrm{(All} \mathrm{traces} \mathrm{are} \mathrm{plotted} \mathrm{to} \mathrm{the}$ same intensity scale.)

as shown in the same table. It may be said that annealing of mechanically polished $\mathrm{Cu}$ substrate caused a recrystallization and grain growth of both surface and bulk of the substrates which influence the wettability by the same effect of the electrolytic polishing.

In order to clarify this phenomena, the mechanically, electrolytically polished, and annealed $\mathrm{Cu}$ substrates were examined by Shimadzu X-ray diffractometer XD-5A and Xray research goniometer VG-108R.

Figure 10 summarizes the results obtained by X-ray analysis. As can be noticed from the figure, the intensity of (111) plane varies according to the surface finish and heat treatment. The relationship between crystal planes of $\mathrm{Cu}$ (f.c.c.) and surface energy is shown by Table $3^{(14)}$. From this table it can be said that the surface energy of (111) plane is smaller than the surface energy of any other plane of f.c.c. crystal.

Figure 11 shows the relationship between

Table 3 Relative surface energy of f.c.c. crystal.

\begin{tabular}{cc}
\hline \hline $\begin{array}{c}\text { Crystal } \\
\text { plane }\end{array}$ & $\begin{array}{c}\text { Relative } \\
\text { surface energy }\end{array}$ \\
\hline$(111)$ & 1.00 \\
$(100)$ & 1.154 \\
$(110)$ & 1.223 \\
$(210)$ & 1.205 \\
\hline \hline
\end{tabular}

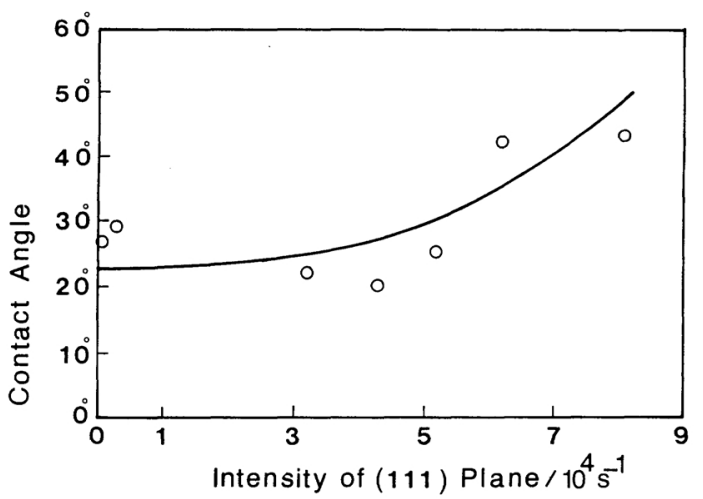

Fig. 11 Relationship between contact angle and intensity of (111) plane of $\mathrm{Cu}$ substrates with various surface treatments.

contact angle and intensity of (111) plane for various surface finish and heat treatment when the wetting tests carried out at $673 \mathrm{~K}$ in $\mathrm{H}_{2}$ atmosphere. From this figure it can be seen that the contact angle increases as the intensity of (111) plane increases, because high intensity of (111) plane means the low surface energy of $\mathrm{Cu}$, and the low surface energy produces a large contact angle according to Young's equation (1).

\section{Effect of cold working}

Some of the solid $\mathrm{Cu}$ substrates were pressed and others were rolled with various degrees of 
working in order to study the effect of cold working on the wettability of solid $\mathrm{Cu}$ by liquid Sn.

Surface roughness of both pressed and rolled $\mathrm{Cu}$ substrates was measured showing values of 1.5 and $2.5 \mu \mathrm{m}$ for the rolled and pressed substrates, respectively.

The wetting tests were carried out at $673 \mathrm{~K}$ in $\mathrm{H}_{2}$ atmosphere. Table 4 summarizes the results obtained. In this table, experiments number 7 and 8 show that the value of the contact angle of the $\mathrm{Cu}$ substrate which pressed after electrolytically polished is twice its value when the substrate was electrolytically polished after pressing. This may indicate that pressing carried out on the $\mathrm{Cu}$ substrates after electrolytic polishing retards the wettability of solid $\mathrm{Cu}$ by liquid $\mathrm{Sn}$.

As can be noticed from Table 4, when the $\mathrm{Cu}$ substrate was pressed after mechanical or electrolytic polishing the contact angle is ranging from $29^{\circ}$ to $43^{\circ}$, i.e., it was bigger than that of the heat treated after pressed substrate which shows a value of $20^{\circ}$. This is because heat treatment decreases the intensity of the (111) plane and correspondingly decreases the contact angle.

Table 4 Effect of cold working on the contact angle between solid $\mathrm{Cu}$ and liquid $\mathrm{Sn}$ at $673 \mathrm{~K}$ in $\mathrm{H}_{2}$ atmosphere.

\begin{tabular}{|c|c|c|c|c|c|c|}
\hline \multirow{3}{*}{$\begin{array}{l}\text { Exp. } \\
\text { No. }\end{array}$} & \multirow{3}{*}{$\begin{array}{c}\text { Cold } \\
\text { working } \\
\text { process }\end{array}$} & \multirow{3}{*}{$\begin{array}{l}\text { Reduction } \\
\text { of } \\
\text { thickness } \\
(\%)\end{array}$} & \multicolumn{4}{|c|}{ Contact angle } \\
\hline & & & \multicolumn{2}{|c|}{$\begin{array}{l}\text { Mechanical } \\
\text { polishing }\end{array}$} & \multicolumn{2}{|c|}{$\begin{array}{l}\text { Electrolytic } \\
\text { polishing }\end{array}$} \\
\hline & & & $\begin{array}{c}\text { Without } \\
\text { H.T. }\end{array}$ & $\begin{array}{l}\text { With } \\
\text { H.T.* }\end{array}$ & $\begin{array}{l}\text { Without } \\
\text { H.T. }\end{array}$ & $\begin{array}{l}\text { With } \\
\text { H.T.* }\end{array}$ \\
\hline 1 & - & 0 & $42^{\circ}$ & $25^{\circ}$ & $20^{\circ}$ & $20^{\circ}$ \\
\hline 2 & Press. & 6 & $33^{\circ}$ & & & \\
\hline 3 & "I & 11 & & & & $20^{\circ \dagger}$ \\
\hline 4 & " & 13 & $29^{\circ}$ & & & \\
\hline 5 & " & 18 & & & $41^{\circ}$ & \\
\hline 6 & " & 18 & $43^{\circ}$ & & & \\
\hline 7 & " & 19 & & & $21^{\text {ott }}$ & \\
\hline 8 & $1 "$ & 20 & & & $44^{\circ}$ & \\
\hline 9 & Roll. & 8 & $36^{\circ}$ & & & \\
\hline 10 & $1 /$ & 23 & & & $15^{\circ}$ & \\
\hline 11 & $" 1$ & 31 & $22^{\circ}$ & & & \\
\hline
\end{tabular}

${ }^{*}$ Heat treatment for $0.06 \mathrm{ks}$ at $1073 \mathrm{~K}$ in $\mathrm{H}_{2}$ atmosphere.

${ }^{\dagger}$ Heat treated for $0.06 \mathrm{ks}$ at $1073 \mathrm{~K}$ after being pressed.

${ }^{\dagger \dagger}$ Electrolytically polished after being pressed.
On the contrary, rolling of solid $\mathrm{Cu}$ substrates which carried out after mechanical or electrolytic polishing caused a decrease of the value of the contact angle as shown in Table 4 , by experiment numbers 9,10 and 11 . The value of surface roughness of the rolled $\mathrm{Cu}$ substrate is smaller than that of the pressed one. This indicates that, it is not the effect of surface roughness which control the flow of liquid Sn on cold worked Cu substrates, since it is well known that if a liquid is able to spread on a smooth solid surface it will spread better if the solid surface is rough, as reported by many investigators. There is another factor which plays a major part in controlling the process. Table 4 indicates that the values of the contact angles of rolled $\mathrm{Cu}$ substrates vary according to the degree of cold working (reduction of thickness). This may be attributed to the change of the crystal orientation at the surface for solid $\mathrm{Cu}$ substrates due to the difference of the degree of working. For the same reason, the values of the contact angles on the rolled $\mathrm{Cu}$ substrates were smaller than those of the pressed $\mathrm{Cu}$ substrates. This could be justified by X-ray analysis. Figure 12 shows the diffraction pattern obtained from variously treated

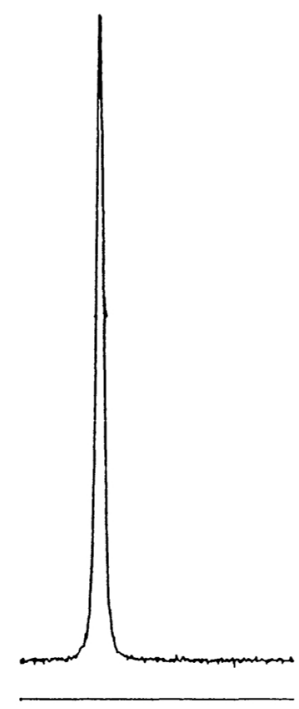

Press.

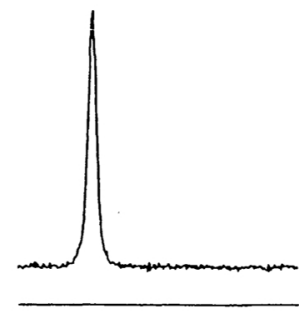

Rol1.
Fig. 12 Diffraction pattern indicating values of 81183 and 32239 c.p.s of the intensity of (111) plane of the pressed and rolled $\mathrm{Cu}$ substrates respectively. 
$\mathrm{Cu}$ substrates when the wetting tests carried out at $673 \mathrm{~K}$ in $\mathrm{H}_{2}$ atmosphere.

From the figure it can be noticed that the intensity of the (111) plane of the pressed $\mathrm{Cu}$ substrates is higher than that of the rolled one. Therefore, as explained above, the higher the intensity of the (111) plane is, the lower the surface energy and correspondingly the larger the contact angle will be.

It may be concluded that the intensity of (111) plane of f.c.c. crystal has a noticable effect on wetting behavior.

In other words, wetting was shown to be highly dependent on the surface orientation of the base metal.

\section{Conclusions}

From this experimental study on the effects of surface finish, heat treatment and cold working on the wettability of solid $\mathrm{Cu}$ by liquid $\mathrm{Sn}$ it can be concluded that:

(1) The behavior of a liquid metal on a solid metallic surface depends entirely upon the condition of the surface.

(2) Electrolytic polishing enhances the wettability, decreases the contact angle and achieves better wetting than mechanical polishing.

(3) It may be recommended that for the practical soldering or coating process, electrolytic polishing is better than mechanical polishing for obtaining a good solderability or coating because of its ability to remove the deformed layer from the surface of the solid adding to its economy and time saving when compared with mechanical polishing.
(4) Annealing of solid $\mathrm{Cu}$ substrates in $\mathrm{H}_{2}$ atmosphere promotes wettability.

(5) Annealing of solid $\mathrm{Cu}$ substrates in $\mathrm{H}_{2}$ atmosphere for $0.06 \mathrm{ks}$ is better for wetting than the annealing for 1.8 or $7.2 \mathrm{ks}$ because the intensity of the (111) plane depends on the annealing period.

(6) Cold working has an influential effect on wetting behaviour.

(7) Wettability of cold worked $\mathrm{Cu}$ substrate by liquid $\mathrm{Sn}$ depends on the process and degree of cold working.

(8) Surface orientation plays an important part in the wettability of solid $\mathrm{Cu}$ by liquid $\mathrm{Sn}$ because of its relation to the surface energy.

\section{REFERENCES}

(1) T. Young: Phil. Trans. Roy. Soc., 95 (1805), 65.

(2) J. W. Gibbs: Trans. Acad., 3 (1878), 343.

(3) R. E. Johnson: J. Phys. Chem., 63 (1959), 1655.

(4) G. L. Bailey and H. C. Watkins: J. Inst. Metals, 80 (1952-1953), 57.

(5) R. J. K. Wassink: J. Inst. Metals, 95 (1967), 38.

(6) J. B. Adamec and R. N. Rhoda: Welding Research Supplement, (1961), 3305.

(7) B. Chalmers and R. H. Wadie: J. Inst. Metals, 66 (1941), 241.

(8) M. G. Nicholas and R. M. Crispin: J. Mat. Sci., 21 (1986), 522.

(9) D. R. Milner: Brit. Weld. J., (1958), 90.

(10) I. Kawakatsu and T. Osawa: J. Japan Inst. Metals, 35 (1971), 463.

(11) I. Kawakatsu and T. Osawa: Tech. Pap. Am. Soc. Tool. Manuf. Eng. No. AD (1974), 1.

(12) Amal. T. Hasouna, K. Nogi and K. Ogino: Trans. JIM, 29 (1988), 748.

(13) L. E. Samuels: J. Inst. Metals, 85 (1956-57), 51.

(14) S. Nakamura: Hyōmen no Butsuri, Kyoritsu-Shuppan, Tokyo, (1985), 119. 